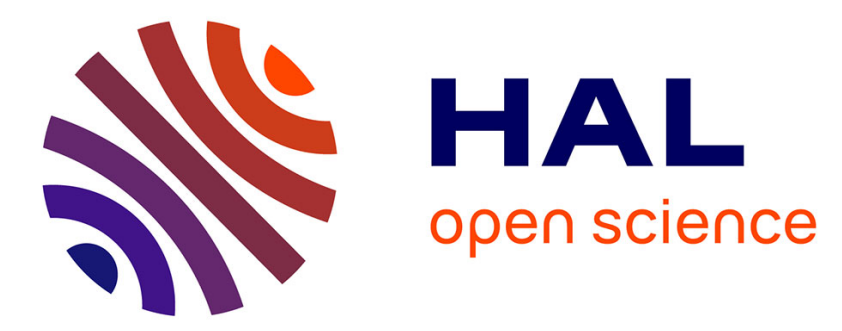

\title{
Ultrasound-guided Angioplasty of Arteriovenous Fistulas for Hemodialysis: Benefits and Limitations
}

Caroline Kazandjian, Vincent Petit, Claire Favier, Béatrice Terriat, Eric Steinmetz

\section{- To cite this version:}

Caroline Kazandjian, Vincent Petit, Claire Favier, Béatrice Terriat, Eric Steinmetz. Ultrasoundguided Angioplasty of Arteriovenous Fistulas for Hemodialysis: Benefits and Limitations. Annals of Vascular Surgery, 2019, 58, pp.32 - 37. 10.1016/j.avsg.2018.10.011 . hal-03486100

\section{HAL Id: hal-03486100 https://hal.science/hal-03486100}

Submitted on 20 Dec 2021

HAL is a multi-disciplinary open access archive for the deposit and dissemination of scientific research documents, whether they are published or not. The documents may come from teaching and research institutions in France or abroad, or from public or private research centers.
L'archive ouverte pluridisciplinaire HAL, est destinée au dépôt et à la diffusion de documents scientifiques de niveau recherche, publiés ou non, émanant des établissements d'enseignement et de recherche français ou étrangers, des laboratoires publics ou privés.

\section{(ㄷ)(1) $\$$}

Distributed under a Creative Commons Attribution - NonCommerciall 4.0 International 


\section{Ultrasound guided angioplasty of arteriovenous fistulas for hemodialysis: Benefits and}

\section{limitations}

Caroline Kazandjian ${ }^{1}$, Vincent Petit ${ }^{2}$, Claire Favier ${ }^{1}$, Béatrice Terriat ${ }^{2}$, Eric Steinmetz ${ }^{1}$ (1)

${ }^{1}$ Service de chirurgie cardiovasculaire et thoracique, CHU François Miterrand, Dijon, France

${ }^{2}$ Service d'angiologie, CHU François Miterrand, Dijon, France $\left(\frac{100}{20}\right.$

Corresponding author: Eric Steinmetz, Department of Cardiovascular and Thoracic Surgery, Dijon University Hospital, 14 rue Paul Gaffarel, 21079 Dijon, France. E-mail: eric.steinmetz@chu-dijon.fr

\section{ABSTRACT}

Background: Ultrasound-guided percutaneous angioplasty of arteriovenous fistulas (AVFs) makes it possible to avoid contrast agents and X-rays, to optimize the puncture site and to locate some stenoses on the fistulography, but is it really useful? Our objective was to report the results of our experience.

Material and methods: Between November 2012 and November 2017, all the patients treated according to this method in our center were collected retrospectively. The surgical indications were an insufficient maturation of the AVF, an increase in the venous pressure, an inadequate outflow, difficulties in puncture, a prolonged bleeding time, a flow drop, or an aneurysmal evolution.

Results: During this period, 50 patients had 72 ultrasound-guided (UG) angioplasties, 64 on native AVFs (88.9\%) and eight on prosthetic AVFs (11.1\%). The technical success rate was $100 \%$. The average preoperative flow of AVFs was $506.8 \pm 302.2 \mathrm{~mL} / \mathrm{min}$ vs $955.9 \pm 371.4$ 
$\mathrm{mL} / \mathrm{min}$ after angioplasty. The mean duration of follow-up was $13.4 \pm 12.9$ months. The cumulative rates of primary, assisted primary and secondary patency were $43.5 \%, 68.8 \%$, $81.5 \%$ at one year and $31.7 \%, 63.9 \%, 76.8 \%$ at two years, respectively.

Conclusion: AVF angioplasty under ultrasound guidance only is feasible, effective and represents an interesting alternative. A controlled study comparing ultrasound guidance with angioplasties performed under conventional angiographic guidance as the reference technique would better clarify the value of this technique.

\section{INTRODUCTION}

Percutaneous angioplasty of arteriovenous fistulas (AVFs) is classically carried out during a dialysis fistulogram with injection of iodinated contrast medium, whether the vascular access is used or not. It can also be performed under ultrasound guidance, making it possible to escape the risk of nephrotoxicity and allergy and to avoid irradiation. We report here the results of our experience of UGA of AVFs. The objective of this study was to describe the technique, to evaluate the results and to discuss its advantages and disadvantages.

\section{MATERIAL AND METHODS}

This was a retrospective monocentric study which included all the patients treated by AVF UG angioplasty between November 2012 and November 2017 in our center. Data were collected from operative reports and pre- and postoperative ultrasound duplex examinations (UDE). Follow-up was carried out by consulting the computerized files of the patients (DxCare ${ }^{\circledR}$ software). The data were collected in a Microsoft Office Excel ${ }^{\circledR} 2016$ spreadsheet, and then analyzed using the IBM SPSS Statistics ${ }^{\circledR}$ version 21 software. Primary patency was defined by the interval of time between UG angioplasty and the thrombosis of the fistula or any intervention carried out to maintain its patency. Assisted primary patency was defined by the interval of time between the UG angioplasty and the thrombosis of the fistula, including the interventions carried out to maintain the patency, and excluding the surgical operations 
that were associated with the closure of the access. Secondary patency was defined by the time between the angioplasty and the stop of the use of the AVF, the thrombosis of the access or its surgical revision. ${ }^{1}$

The indications of the procedure were defects of maturation (i.e. any AVF that cannot be used six weeks after its creation) diagnosed by a systematic UDE, an increase in the venous pressure, an insufficient drainage, difficulties of puncture during dialysis, an increased bleeding time, a drop of flow of the AVF, or the development of aneurysms. The localization as well as the degree and the repercussion of the stenoses were diagnosed by UDE. In the same way, central venous thromboses were highlighted by UDE, directly if they were located in an accessible zone or indirectly in the presence of evocative remote data. The diagnosis was then confirmed during the fistulogram or by an angio-CT when needed. The cases that were untreated with ultrasound only were central venous stenoses, patients with calcified arterial lesions or venous stenoses longer than $5 \mathrm{~cm}$.

All the procedures were performed in a surgical unit under local anesthesia, possibly supplemented by a neuroleptanalgesy. The surgeon was accompanied by our contact angiologist in charge of AVFs, and both were gowned in sterile dressing for the procedure (Fig. 1). The angiologist first researched the lesions before puncturing the vessel under local anesthesia. A 4F-6F sheath was then placed in an anterograde or retrograde way according to the location of the lesion. A bolus of $50 \mathrm{UI} / \mathrm{Kg}$ of heparin was then injected intravenously. A 0.035 or 0.018 guidewire was used to cross the stenoses, sometimes with the help of a straight Impress $^{\circledR}$ catheter $\left(\right.$ Merit ${ }^{\circledR}$ ) or of a Ber $2^{\circledR}$ catheter (Boston Scientific Corporation $^{\circledR}$ ).

The size of the balloon was defined with UDE, according to the diameter of the adjacent vessel and the length of the stenosis. We used Passeo- $18^{\circledR}$ balloons (Biotronik ${ }^{\circledR}$ ) with 0.018 wires, Armada ${ }^{\circledR}$ balloons $\left(\right.$ Abbott $^{\circledR}$ ) with 0.035 wires and Mustang ${ }^{\circledR}$ balloons (Boston ${ }^{\circledR}$ ) for resistant lesions requiring a high pressure of inflation. The length of the lesions was 20-60 
$\mathrm{mm}$ and their diameter was $5-8 \mathrm{~mm}$. Inflation was systematically carried out during three min. After angioplasty the balloon was withdrawn and the wire was left in place. The angiologist measured the size of the vessel after angioplasty, searched for a residual stenosis and evaluated the flow of the AVF whenever possible (Fig. 2). After withdrawal of the material, a manual compression was applied for 10 minutes.

\section{RESULTS}

Between November 2012 and November 2017, 50 patients had 72 interventions for UG AVF angioplasty, 17 women (34\%) and 33 men (66\%). Mean age was $66.1 \pm 12$ years (median 64.5 years). Sixty-four procedures were carried out on native AVFs (88.9\%) and eight on prosthetic AVFs (partial or total; 11.1\%). Thirty-one of the native FAVs were radiocephalic AVFs (43.1\%), 20 were humerocephalic AVFs (27.8\%), five were cubitocubital AVFs (6.9\%), four humerobasilic AVFs (5.6\%), two radiobasilic AVFs (2.8\%) and two cubitobasilic AVFs (2.8\%). Twenty-three angioplasties were carried out for an insufficient maturation (31.9\%). The average time between the creation of the fistula and UG angioplasty was $18 \pm 36.7$ months ([1-249 months], median six months).

Overall, 108 stenoses were treated. The locations of the dilated sites are described in Tables I and II. Six patients underwent three angioplasties, five underwent two procedures and thirty-eight were dilated only once. One patient underwent six procedures on the same AVF, which was associated twice with a thrombectomy. The average time between the first and the second dilation was $9 \pm 8$ months ([1-23 months], median 6.5 months), and between the second and the third, it was 7.7 \pm 5 months ([1-12 months], median nine months).

In total, eight stents were implanted. Four patients received one stent (two in the inflow artery $\left[\right.$ Prokinetic $^{\circledR}$ stents, Biotronik ${ }^{\circledR}$ ), and two in the drainage vein $\left(\right.$ Optimed $^{\circledR}$ and Boston $^{\circledR}$ stents), and two patients received two stents $\left(\right.$ Boston $^{\circledR}$ Express $^{\circledR}$ and Pulsar ${ }^{\circledR}$ Biotronik $^{\circledR}$ stents, in the outflow vein of the AVF). In ten cases, the UG angioplasty was 
101

102 UDE, three thrombectomies, two replacements of a venous segment, one repair of an 103 arteriovenous anastomosis and one aneurysmorraphy.

\section{Technical success and complications}

105

The technical success rate of the angioplasties was 100\%. Nine complications $(12.5 \%)$ occurred, with three hematomas of the venous wall and one rupture treated by a prolonged

107 low pressure inflation, three dissections on the dilated site (one treated with an additional 108 prolonged angioplasty, one by the implantation of one stent and another requiring the realization of a short venous bypass to treat the occlusion of the dissected zone), one peroperative thrombosis leading to the abandonment of the fistula, and another thrombosis treated by thrombolysis and a new prolonged angioplasty. Wall hematomas could be 112 diagnosed quickly by UDE (much more difficult with a fistulogram), which allowed their 113 prompt treatment. In the same way, UDE makes it possible to control the absence of leak 114 when inflating the balloon, which avoids the risk of over-dilatation, potentially noxious for the venous wall.

\section{Clinical success}

117 Fourteen angioplasties were carried out in patients not yet on dialysis. Among the 58 118 remaining procedures, five did not allow to use the AVF thereafter, which corresponds to a 119 clinical success of $91.4 \%$.

\section{Ultrasound parameters}

121 After exclusion of the occluded accesses, the average flow of the fistulas was $536.7 \pm 283.7$ $122 \mathrm{~mL} / \mathrm{min}([100-1600 \mathrm{~mL} / \mathrm{min}]$, median $500 \mathrm{~mL} / \mathrm{min})$ before angioplasty and $930.6 \pm 348.3$ $123 \mathrm{~mL} / \mathrm{min}([300-2000 \mathrm{~mL} / \mathrm{min}]$, median $850 \mathrm{~mL} / \mathrm{min})$ after angioplasty. For prosthetic AVFs, 124 the flow increased on average by $466.7 \pm 115.4 \mathrm{~mL} / \mathrm{min}$ (median $400 \mathrm{~mL} / \mathrm{min}$ ). For mature 
native AVFs, the post procedure flow went up by $395 \pm 375 \mathrm{~mL} / \mathrm{min}$ on average ([- 450-1550 $\mathrm{mL} / \mathrm{min}$ ], median $400 \mathrm{~mL} / \mathrm{min}$ ). Lastly, for the non-mature native AVFs, the flow was increased by $314.6 \pm 205.6 \mathrm{~mL} / \mathrm{min}$ on average ([0-700 $\mathrm{mL} / \mathrm{min}]$, median $275 \mathrm{~mL} / \mathrm{min})$.

\section{Follow-up}

The AVFs that were treated several times were analyzed only once, starting from the first angioplasty. Thus, fifty-two fistulas were analyzed, with two patients treated by balloon dilatation on another AVF after the abandonment of the first one. The average duration of follow-up was $13.4 \pm 12.9$ months ([1-45 month], median 8 months). Five patients received a kidney transplant. The fistula was abandoned in seven other cases, and 12 patients died. The cumulative rates of primary, assisted primary and secondary patency were $43.5 \%, 68.8 \%$, and $81.5 \%$ at one year, and $31.7 \%, 63.9 \%$, and $76.8 \%$ at two years, respectively (Fig. 3).

\section{DISCUSSION}

Functioning AVFs often develop stenoses, generally on the venous outflow tract, which require angioplasty to maintain the optimal patency required to initiate and continue hemodialysis. Angioplasty is usually carried out classically under fluoroscopy with injection of a iodinated contrast product, which exposes to an allergic risk and a renal toxicity. ${ }^{2,3}$ The same procedure performed under ultrasound guidance avoids iodine, which is particularly interesting in chronic renal failure patients who are not yet on dialysis, but also after the beginning of hemodialysis to preserve the kidneys. UDE makes it possible to optimize the site of puncture, offers a significant gain of examination time, ${ }^{4}$ and detects some stenoses that are not visible on a fistulogram. ${ }^{5}$

The procedures performed in this study led to a technical success of $100 \%$, through a careful selection of the patients. We excluded central venous stenoses, the long stenoses and extremely calcified arterial lesions. Several studies proved the feasibility of this technique, 
with technical success rates varying from 93 to $100 \%$, and some physicians use it in their

150 office outside the hospital environment. ${ }^{6-10}$ We made the choice to use this technique only for 151 rather short stenoses, with balloons measuring less than six $\mathrm{cm}$ in length. We think that longer

152 lesions are less accessible to UG dilatation, just as occlusions, even if some authors reported

153 the treatment of longer stenoses. ${ }^{8}$ We observed three hematomas and one rupture of the 154 dilated outflow vein, which did not affect the patency. These complications occurred exclusively on non-mature AVFs, thus pointing the fragility of recently arterialized veins. The complications which we met are classically described in the literature. Arterial spasms have also been reported, but we did not observe this complication. ${ }^{8-11}$

Our results are incomplete because of the retrospective character of the study, which did not allow collecting enough data, in particular the arterial resistivity index and the peak systolic velocity, which are often lacking in the pre- or postoperative examination, or for the patients followed outside our center. We observed satisfactory patency rates, in agreement with the data of the literature, but the interpretation of the results remains limited by the small population size of our study. ${ }^{2,12,13} \mathrm{We}$ did not seek factors influencing the patency of the fistulas, in particular because of the lack of collected data, but this analysis should be addressed in our next research. Several stenoses had to be dilated several times. These iterative percutaneous angioplasties extend the lifespan of the access, avoid the need for open surgery or the creation of a new AVF and preserve the venous capital. If necessary, the creation of a more proximal access can create ischemic phenomena, in particular in older and diabetic patients, and must be avoided in case of central venous stenosis or occlusion. ${ }^{14}$

Eight stents were implanted in these procedures, without the use of fluoroscopy. We had no problems with the deployment of the stents but the gesture proved more delicate to carry out, because the stent is hidden when it is contained in its sheath. 
We chose to carry out these procedures in the operating theatre to decrease the risk of

174 septic contamination. The ultrasound unit occupies less room than a C-arm with an easier 175 handling. Intraoperative ultrasound control makes it possible to immediately analyze the anatomical and hemodynamic results of angioplasty (measurement of the flow and of the peak systolic velocity), which reduces the number of balloon inflations and can detect residual stenoses that are really less visible in fluoroscopy. The size of the balloon should ideally be selected according to the diameter of the vessel which is perfectly measured by echography. Complications are easily detectable, the puncture site can be immediately checked after the withdrawal of the material, and a leak can be optimally compressed under ultrasound control. However, this examination requires an experienced operator.

\section{CONCLUSION}

Ultrasound guided angioplasty of arteriovenous fistulas is feasible and effective but present some limits. The procedure is more delicate when the implantation of a stent is required, but it still entirely possible. No study to date compared ultrasound guidance with conventional angiography, but this technique could bring significant benefits, without fully replacing the fistulogram, in particular in in the presence of central venous stenoses, very tortuous or aneurysmal vessels, heavily calcified arteries, or long occlusive lesions. A controlled study comparing ultrasound-guided angioplasty with the conventional angiographic technique would clarify the interest of this technique.

\section{REFERENCES}

1. Gray RJ, Sacks D, Martin LG, Trerotola SO, Reporting Standards for Percutaneous Interventions in Dialysis Access. J Vasc Interv Radiol 2003;14:S433-S442.

2. Malka KT, Flahive J, Csizinscky A, Aiello F, Simons JP, Schanzer A, et al. Results of repeated percutaneous interventions on failing arteriovenous fistulas and grafts and 
199 3. Napoli M, Prudenzano R, Russo F, Antonaci AL, Aprile M, Buongiorno E. Juxtaanastomotic stenosis of native arteriovenous fistulas: surgical treatment versus percutaneous transluminal angioplasty. J Vasc Access. 2010 Oct-Dec:11:346-51.

4. Doelman C, Duijm LEM, Liem YS, Froger CL, Tielbeek A V., Donkers-van Rossum $\mathrm{AB}$, et al. Stenosis detection in failing hemodialysis access fistulas and grafts: Comparison of color Doppler ultrasonography, contrast-enhanced magnetic resonance angiography, and digital subtraction angiography. J Vasc Surg. 2005 Oct;42:739-46.

5. Salman L, Ladino M, Alex M, Dhamija R, Merrill D, Lenz O, et al. Accuracy of ultrasound in the detection of inflow stenosis of arteriovenous fistulae: results of a prospective study. Semin Dial. 2010 Feb;23:117-21.

6. Ascher E, Hingorani A, Marks N. Duplex-guided balloon angioplasty of failing or nonmaturing arterio-venous fistulae for hemodialysis: a new office-based procedure. $\mathrm{J}$ Vasc Surg [Internet]. 2009 Sep;50:594-9.

7. Fox D, Amador F, Clarke D, Velez M, Cruz J, Labropoulos N, et al. Duplex guided dialysis access interventions can be performed safely in the office setting: techniques and early results. Eur J Vasc Endovasc Surg Off J Eur Soc Vasc Surg. 2011 Dec;42:833-41.

8. Gorin DR, Perrino L, Potter DM, Ali TZ. Ultrasound-guided angioplasty of autogenous arteriovenous fistulas in the office setting. J Vasc Surg. 2012 Jun;55:1701-5.

218 9. Gallagher JJ, Boniscavage P, Ascher E, Hingorani A, Marks N, Shiferson A, et al. 219 Clinical experience with office-based duplex-guided balloon-assisted maturation of arteriovenous fistulas for hemodialysis. Ann Vasc Surg. 2012 Oct;26:982-4.

221 10. Wakabayashi M, Hanada S, Nakano H, Wakabayashi T. Ultrasound-guided endovascular treatment for vascular access malfunction: results in 4896 cases. J Vasc 
Access. 2013 Sep;14:225-30.

224 11. DerDerian T, Hingorani A, Boniviscage P, Carollo A, Ascher E. Acute complications after balloon-assisted maturation. Ann Vasc Surg. 2014;28:1275-9.

12. Heye S, Maleux G, Vaninbroukx J, Claes K, Kuypers D, Oyen R. Factors influencing technical success and outcome of percutaneous balloon angioplasty in de novo native hemodialysis arteriovenous fistulas. Eur J Radiol. 2012 Sep;81:2298-303.

13. Kim SM, Ko HK, Noh M, Ko G-Y, Kim M-J, Kwon T-W, et al. Factors Affecting Patency Following Successful Percutaneous Intervention for Dysfunctional Hemodialysis Vascular Access. Ann Vasc Surg. 2017;47:54-61.

14. Turmel-Rodrigues L. Dilatation is usually the best treatment for stenosis of the arteriovenous hemodialysis fistula. Nat Clin Pract Nephrol. 2008;4:116-7.

\section{Legend of figures}

Fig. 1. Installation of the patient.

Fig. 2. Ultrasound imaging of each stage of the operation. A. Stenosis on the outflow vein of

B. Visualization of the introducer.

C. Visualization of the guidewire in the introducer.

D. Stenotic imprint during balloon inflation. E. Removal of the stenosis by angioplasty. F. Deflation of the balloon. G. End result showing the disappearance of the stenosis and a homogeneous regular flow.

Fig. 3. Cumulative patency rates (Kaplan Meier). A. Cumulative primary patency rate. B.

244 Cumulative assisted primary rate. C. Cumulative secondary patency rate. 


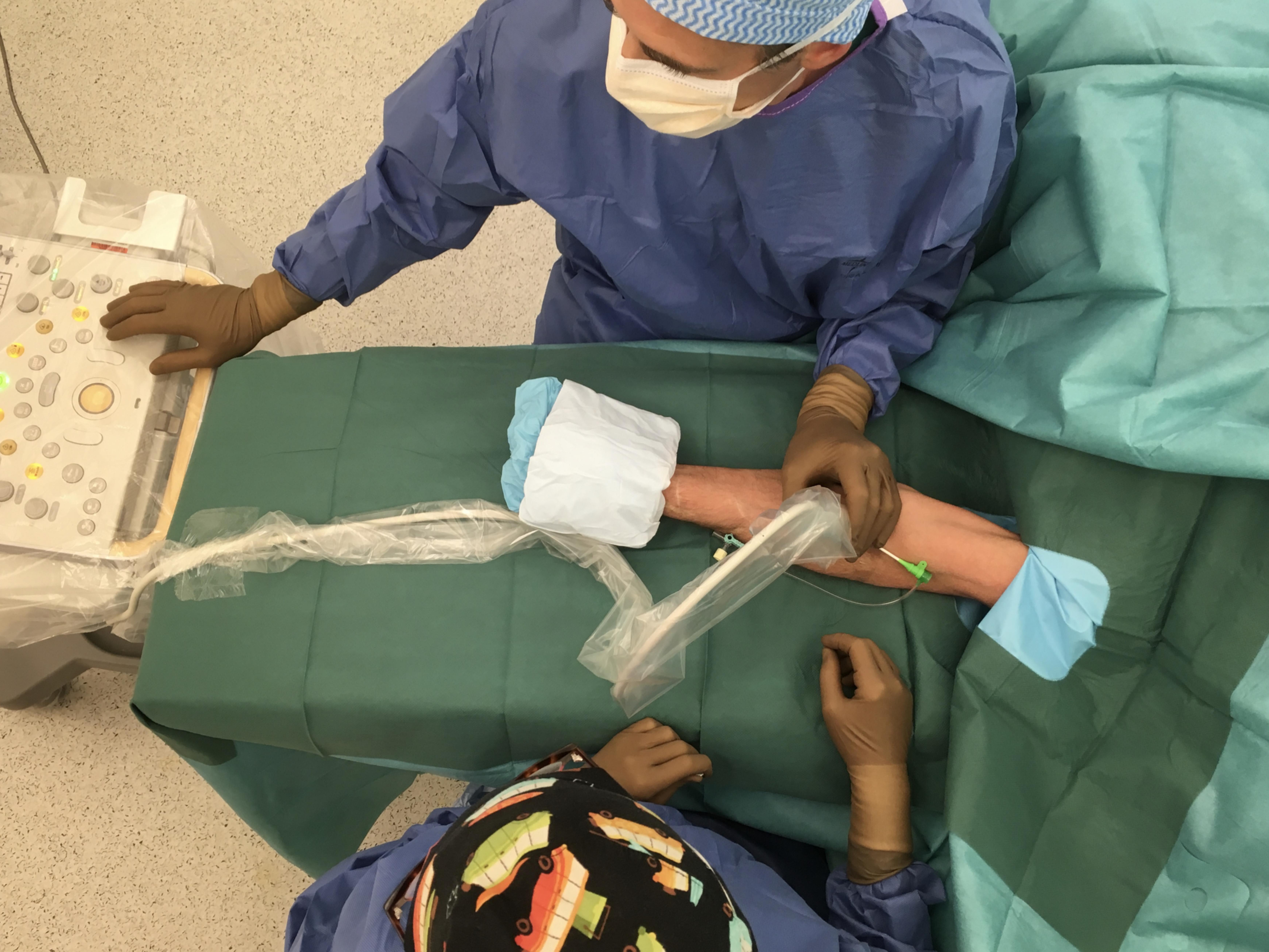




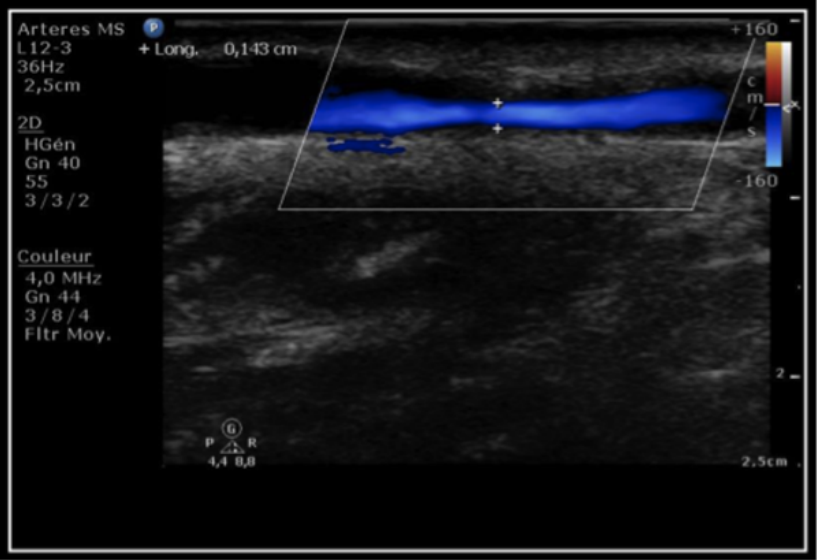


Arteres MS

L.12-3

$55 \mathrm{~Hz}$

$2,5 \mathrm{~cm}$

2D

HGên

Gn 40

55

$3 / 3 / 2$
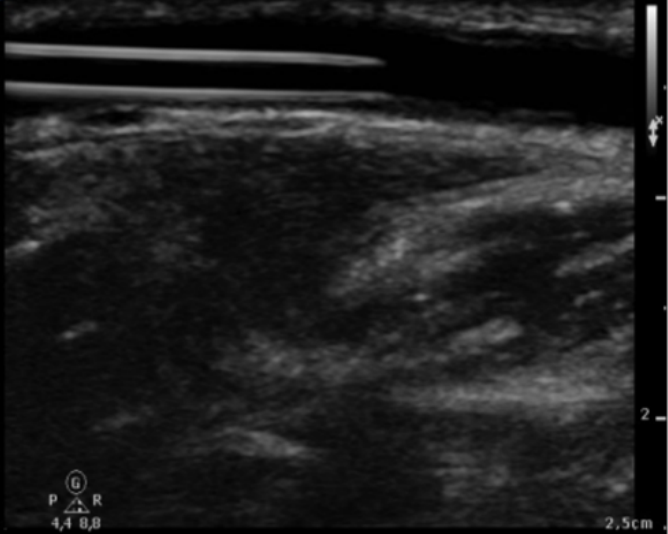
Arteres MS

$\mathrm{L} 12-3$
$55 \mathrm{~Hz}$
$2,0 \mathrm{~cm}$
$2 \mathrm{D}$
$\mathrm{HGén}$
$\mathrm{Gn} 40$
55
$3 / 3 / 2$

P

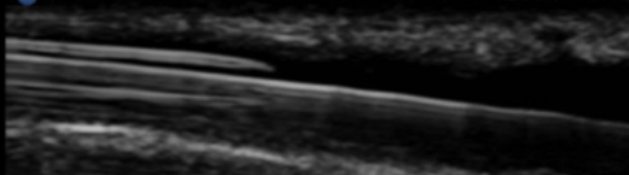

-

(6)

P A.R

$4,48,8$

$2,0 \mathrm{~cm}$ 
TSA Optim

L12-3

$104 \mathrm{~Hz}$

$2 \mathrm{~cm}$

2D

F 2

Gn 63

$232 \mathrm{~dB} / \mathrm{C} 4$

$\mathrm{F} / 3 / 3$

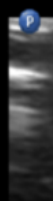

${ }^{*}{ }^{P} \int_{3,0}^{6} R$
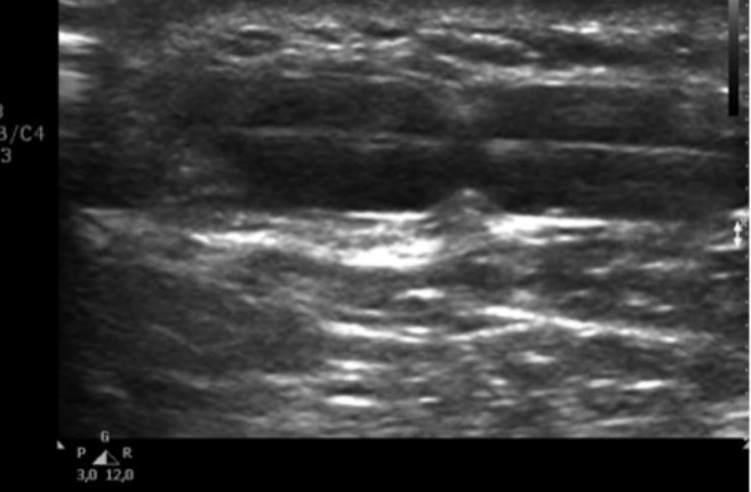


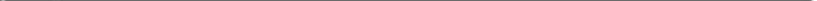


Arteres MS

L $12-3$

$55 \mathrm{~Hz}$

$2,0 \mathrm{~cm}$

2D

HGén

Gn 40

55

$3 / 3 / 2$
D

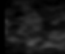

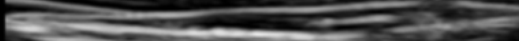

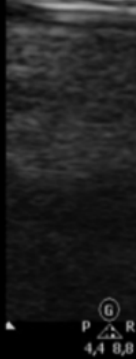
$2,0 \mathrm{~cm}=$

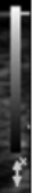
$1=$

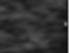
$-$ 


\section{Arteriel}

12-3

25117

$3 \mathrm{~cm}$

2D

HGèn

Gn 40

55

$3 / 3 / 2$

Couleur

4,0 $\mathrm{MHz}$

Gn 51

$3 / 8 / 4$

fitr Moy.
P
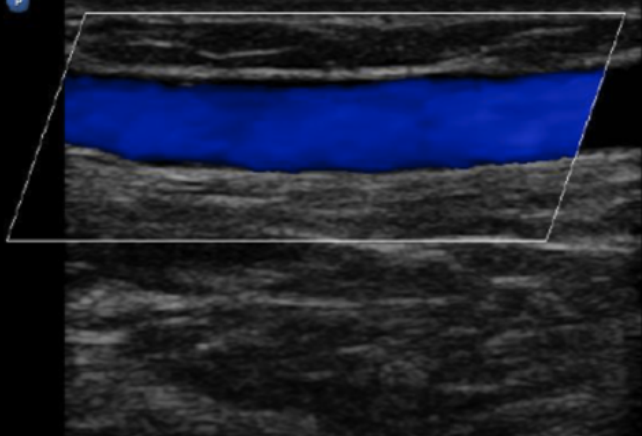

-

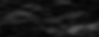

(6)

P $\mathrm{R}$

4,4 8. 8 


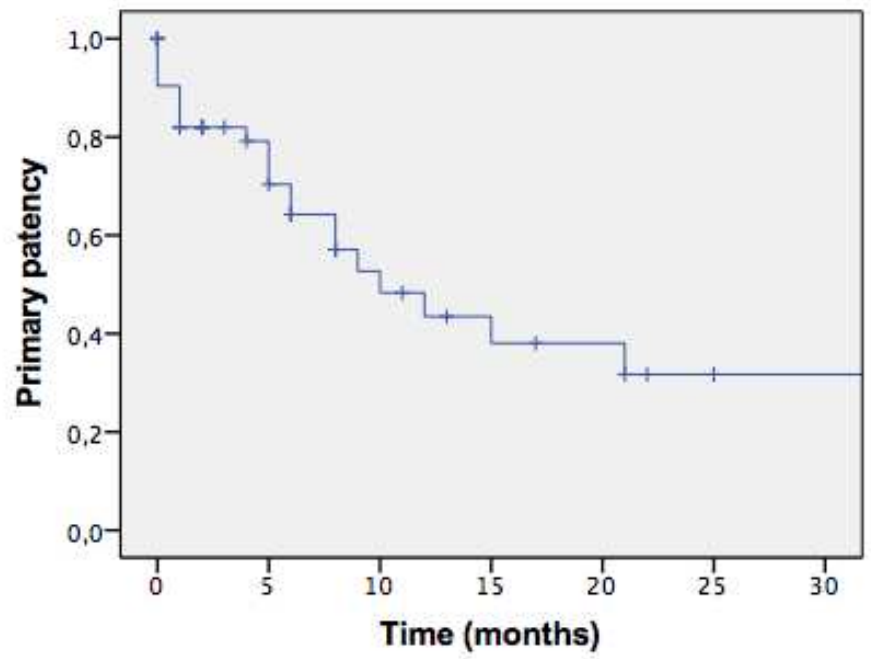

\begin{tabular}{|c|c|c|}
\hline & 12 months & 24 months \\
\hline $\begin{array}{c}\text { N of patients at risk } \\
\text { (total n of patients = 52) }\end{array}$ & 40 & 28 \\
\hline Patency rate (\%) & $43.5 \pm 9.4$ & $31.7 \pm 9.9$ \\
\hline
\end{tabular}




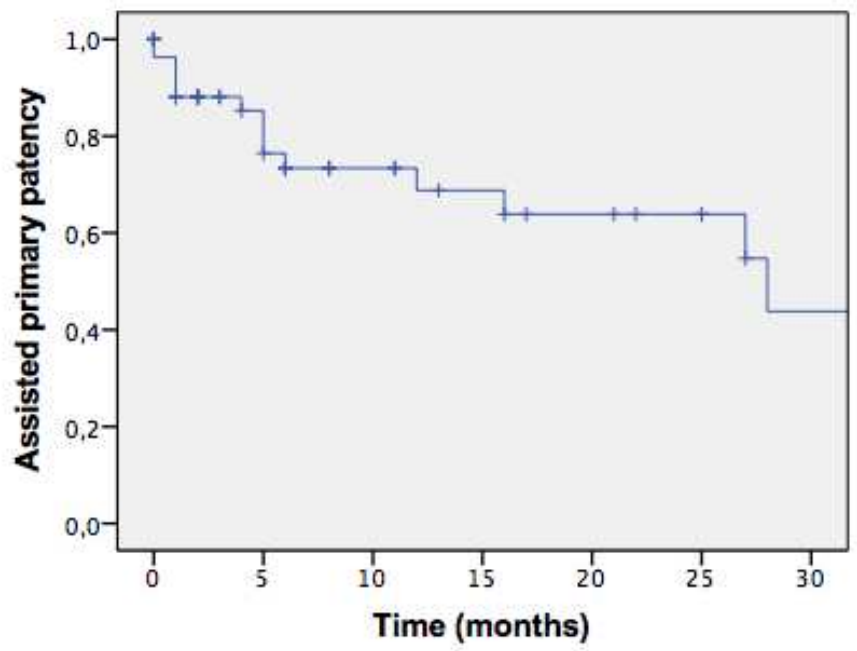

\begin{tabular}{|c|c|c|}
\hline & 12 months & 24 months \\
\hline $\begin{array}{c}\text { N of patients at risk } \\
\text { (total n of patients = 52) }\end{array}$ & 42 & 30 \\
\hline Patency rate (\%) & $68.8 \pm 8$ & $63.9 \pm 8.8$ \\
\hline
\end{tabular}




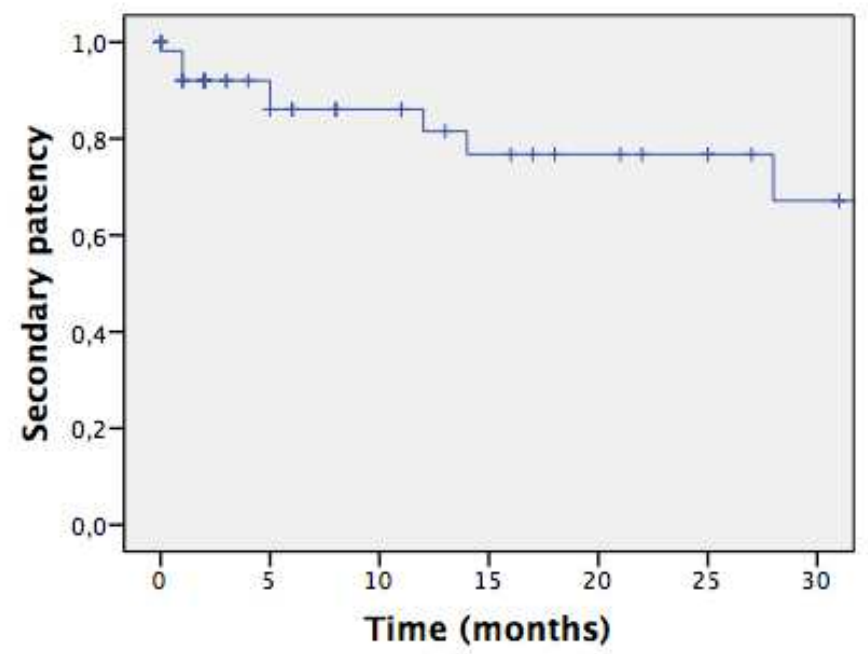

\begin{tabular}{|c|c|c|}
\hline & 12 months & 24 months \\
\hline $\begin{array}{c}\text { N of patients at risk } \\
\text { (total n of patients = 52) }\end{array}$ & 42 & 30 \\
\hline Patency rate (\%) & $81.5 \pm 6.8$ & $76.8 \pm 7.9$ \\
\hline
\end{tabular}


Table I. Sites of angioplasty in native AVFs

Site of angioplasty

Native AVFs

Mature AVFs Defect in maturation

Juxta-anastomotic

11

Post-anastomotic

2

0

Outflow vein

53

19

Artery

2

1 


\begin{tabular}{lc}
\hline \multicolumn{1}{l}{ Site of angioplasty } & Prosthetic \\
& AVF \\
\hline Graft/vein anastomosis & 5 \\
Intragraft & 1 \\
Outflow vein & 2 \\
Artery & 2 \\
\hline
\end{tabular}

Table II. Sites of the angioplasties in prosthetic AVFs 